\title{
Dissociating Striatal and Hippocampal Function Developmentally with a Stimulus-Response Compatibility Task
}

\author{
B. J. Casey, ${ }^{1}$ Kathleen M. Thomas, ${ }^{1}$ Matthew C. Davidson, ${ }^{1}$ Karen Kunz, ${ }^{1}$ and Peter L. Franzen ${ }^{2}$ \\ 'Sackler Institute for Developmental Psychobiology, Weill Medical College of Cornell University, New York, New York \\ 10021, and 2Department of Psychology, University of Arizona, Tucson, Arizona 85721
}

\begin{abstract}
The current study examined the development of cognitive and neural systems involved in overriding a learned action in favor of a new one using a stimulus-response compatibility task and functional magnetic resonance imaging. Eight right-handed adults (mean age, 22-30 years), and eight children (7-11 years) were scanned while they performed a task. Both children and adults were less accurate for incompatible stimulus-response mappings than compatible ones; the children's performance was significantly worse. The comparison of the incompatible and compatible conditions showed large volumes of activity in the ventral prefrontal cortex, ventral caudate nucleus, thalamus, and hippocampus. Striatal activity correlated with the percentage of errors in overriding the old stimulus-response association. The hippocampal activity correlated with the reaction time
\end{abstract}

to make a response to a new stimulus-response mapping that required the reversal of a prior association between a stimulus and a response location. Developmental differences were observed in the volume of striatal/pallidal and hippocampal/parahippocampal activity in that these regions were larger and extended more ventrally in children relative to adults. These results suggest that with maturation and learning, projections to and from these regions may become more refined and focal. Moreover, these findings are consistent with the role of ventral frontostriatal circuitry in overriding habitual and well learned actions and hippocampal systems in learning and reversing associations between a given stimulus and spatial location.

Key words: development; basal ganglia; hippocampus; imaging; learning; fMRl; children
The ability to override competing actions is a key component of cognitive functioning (Kahneman et al., 1983; Baddeley, 1986; Shallice, 1988; Cohen and Servan-Schreiber, 1992; Desimone and Duncan, 1995); it becomes more efficient with age (Harnishfeger and Bjorkland, 1993). In other words, immature cognition is characterized by greater susceptibility to interference from competing actions (Diamond, 1990; Brainerd and Reyna, 1993; Dempster, 1993; Casey et al., 2001, 2002; Munakata and Yerys, 2001), as evidenced in children when performing Stroopinterference tasks (Tipper et al., 1989), card sorting (Zelazo et al., 1996; Munakata and Yerys 2001), and go-no-go tasks (Luria, 1961; Casey et al., 1997a,b; Vaidya et al., 1998). In all cases, children have more difficulty making the correct response when there is interference from competing response alternatives.

Overriding well learned actions in favor of new ones and the development of neural subsystems underlying this ability is the focus of this paper. In essence, how does the less mature system recruit brain regions when making a new response to a given stimulus relative to making a well learned response to that same stimulus (i.e., stimulus-response incompatibility)? This ability involves both overriding an old association while simultaneously learning a new one. The ability to shift between behavioral sets has been linked to ventral frontostriatal circuitry (Alexander et al., 1986). Lesions in this circuitry can result in difficulty shifting out of a behavioral set (Iversen and Mishkin, 1970). Imaging

Received March 8, 2002; revised May 30, 2002; accepted June 27, 2002.

This work was supported in part by awards 5-K01 MH01297-03 and 1 R01 MH64155-01 from the National Institute of Mental Health to B.J.C.

Correspondence should be addressed to Dr. B. J. Casey, Sackler Institute for Developmental Psychobiology, Weill Medical College of Cornell University, 1300 York Avenue, Box 140, Suite F-1332, New York, NY 10021. E-mail bjc2002@ med.cornell.edu.

Copyright (C) 2002 Society for Neuroscience $\quad 0270-6474 / 02 / 228647-06 \$ 15.00 / 0$ studies have implicated this circuitry in learning new sequences or stimulus-response mappings relative to learned sequences (Taylor et al., 1993; Berns et al., 1997; Rauch et al., 1998). Finally, clinical disorders characterized by difficulty shifting a behavioral set [e.g., obsessive-compulsive disorder (OCD)] show abnormally high metabolism in this circuitry (Baxter et al., 1988; Swedo et al., 1989) and appear to rely on alternative learning systems involving the hippocampus rather than frontostriatal circuitry when learning a sequenced response (Rauch et al., 2001).

A key question of this study is how an immature system recruits brain regions when learning new stimulus-response associations. First, based on the existing animal, clinical, and imaging literature, we hypothesized that children would have more difficulty overriding an old stimulus-response mapping in favor of a new one and that frontostriatal activity would correlate with development of this ability. Second, we hypothesized that frontohippocampal activity would be involved in learning a new set of response locations. Finally, based on our own work and that of others (Casey et al., 1997b; Hertz-Pannier et al., 1997), we hypothesized that activity associated with forming new associations would be more diff use and less focal for children in these respective frontostriatal and hippocampal circuits, but that similar brain regions would be recruited across age groups. Thus, the current study examines the development of neural circuitry involved in overriding a stimulus-response mapping and learning a new one using functional magnetic resonance imaging (fMRI) and a stimulus-response compatibility task.

\section{MATERIALS AND METHODS}

Subjects. Eight right-handed adults (three female; mean age, 24.5 years, range, 22-30) and eight right-handed children (four female; mean age, 8.8 years, range, $7-11$ ) were scanned. All subjects were screened for a 


\begin{tabular}{|c|c|c|c|c|c|}
\hline \multirow[b]{2}{*}{ Regions of interest } & \multicolumn{3}{|c|}{ Talairach coordinates } & \multirow[b]{2}{*}{ Maximum $F$ ratio } & \multirow[b]{2}{*}{ Volume, $\mathrm{mm}^{3}$} \\
\hline & $X$ & $Y$ & $Z$ & & \\
\hline \multicolumn{6}{|l|}{ Activations } \\
\hline Right thalamus & 14 & -17 & 6 & 54.08 & 3320 \\
\hline Right basal ganglia & 10 & 3 & 8 & 33.81 & 1953 \\
\hline Right hippocampus & 21 & -33 & -7 & 30.55 & 1807 \\
\hline Right insula & 40 & 12 & 4 & 41.81 & 1758 \\
\hline Right prepostcentral gyrus (4/1) & 30 & -19 & 34 & 54.08 & 1123 \\
\hline Right inferior parietal (40) & 28 & -48 & 32 & 42.45 & 830 \\
\hline Left fusiform gyrus & -49 & -47 & -17 & 24.60 & 732 \\
\hline Left insula & -38 & 6 & 3 & 18.35 & 586 \\
\hline Left lateral orbital/inferior frontal gyrus (47) & -38 & 17 & -3 & 22.91 & 488 \\
\hline Right middle frontal gyrus (6) & 44 & 4 & 50 & 18.69 & 488 \\
\hline Left cerebellum & -18 & -50 & -46 & 17.43 & 439 \\
\hline \multicolumn{6}{|l|}{ Deactivations } \\
\hline Right cingulate gyrus (31) & 5 & -52 & 37 & 13.36 & 244 \\
\hline Right superior temporal gyrus (22) & 54 & -38 & 14 & 14.03 & 195 \\
\hline
\end{tabular}

history of any contraindication for MRI. Written informed consent was obtained from subjects before the scans were performed.

Behavioral paradigm. Subjects were shown a single centrally presented digit on each trial $(1,2$, or 3$)$. The stimulus duration was $500 \mathrm{msec}$, with an interstimulus interval of $1500 \mathrm{msec}$. The subject's task was to press one of three buttons that corresponded to the presented digit. In the stimulus-response-compatible condition, subjects pressed the first button for a 1 , the second button for a 2 , and the third button for a 3 (i.e., 1-2-3 mapping). In the incompatible mapping condition, subjects had to shift and maintain a new behavioral set, either 3-1-2 or 2-3-1. For example, in the 3-1-2 mapping, subjects pressed the first button for a 3 , the second button for a 1 , and the third button for a 2 . In a simple rest condition, subjects passively watched as the digit 1,2 , or 3 appeared on the screen, but pressed no button. Each condition (compatible, incompatible, and rest) was presented in $60 \mathrm{sec}$ blocks with 30 trials per block in an ABCCBA design run four times. Because of technical problems behavioral data were unavailable for five subjects (two adults and three children).

Image acquisition. Subjects were first acclimated to the MRI environment in a simulator. Next, $\mathrm{T}_{1}$-weighted images [spin echo, echo time (TE) minimum, repetition time (TR) $500,256 \times 256,5 \mathrm{~mm}$ whole brain] were acquired in the same location as the echo planar images for localization purposes. Echo planar images (echo planar gradient echo sequence, TE 40 , TR 6000 , flip $90^{\circ}$, acquisition matrix $128 \times 64,26$ coronal slices) were acquired in twenty-six $5 \mathrm{~mm}$ contiguous coronal slice locations using a GE 1.5 T scanner (General Electric, Wilmington, MA) with 66 images per slice across four runs of the experimental conditions in an ABCCBA ordering. Each $6000 \mathrm{msec}$ whole-brain image acquisition corresponded to three $2000 \mathrm{msec}$ behavioral trials

Image processing and analysis. All scans were corrected for motion using three-dimensional motion correction automated image registration (Woods et al., 1992) and cross-registered to a representative male child subject's anatomical scan. Because variance maps did not differ between groups, voxelwise ANOVAs were performed on the pooled data comparing the eight adults with the eight children to examine the effects of age group and mapping condition. Significant regions were identified by $F$ ratios with $p<0.001$ and a minimum cluster size of 5 voxels in the scanned plane (coronal).

\section{RESULTS}

\section{Behavioral results}

Overall, children had more difficulty with the incompatible stimulus-response mappings than adults, as evidenced by poorer mean accuracy (99 vs 78\%; $t=5.75 ; p<0.0001$ ). Children and adults were slower to respond during incompatible mappings of 3-1-2 or
2-3-1 than during the compatible mapping of 1-2-3, but not significantly so (741 and $890 \mathrm{msec} ; t=1.38 ; p<0.17$ ). Calculations of percent differences in reaction time and simple difference scores between these conditions showed similar costs associated with the incompatible mapping relative to the compatible one for both children and adults (20 and 20\%, $t=0.01, p<0.99 ; 193$ and $111 \mathrm{msec}, t=1.53, p<0.16)$.

\section{Imaging results}

A voxelwise 16 (subjects) $\times 2$ (condition) ANOVA comparing the compatible and rest conditions was performed to determine sensorimotor systems involved in performing the task without the manipulation of stimulus-response incompatibility. This analysis showed two regions of significant activity. Across all subjects the compatible mapping condition produced significant activity in left primary motor cortex (BA 4) and the right cerebellum related to a right-hand button press during the task.

The main effect of condition was tested with a voxelwise $16 \times 2$ ANOVA comparing the incompatible and compatible stimulus-response mappings. The main effects of condition are shown in Table 1 . The largest volumes of signal change were shown in the basal ganglia, inferior frontal/insula cortex, and thalamus, as well as the hippocampus (Fig. 1). A separate time (four runs) $\times$ condition ANOVA showed no changes in these regions as a function of time on task or activity in other prefrontal regions.

The interaction of group $\times$ condition was tested with a third voxelwise ANOVA. This analysis showed a significant interaction in the extent of activity in the basal ganglia, hippocampal region, and premotor cortex. First, children showed larger volumes of activity than adults in hippocampal and parahippocampal regions as well as the basal ganglia during the incompatible mapping condition. These regions extended more ventrally in children. Second, adults showed an increased signal change in premotor cortex for the incompatible mappings that was not shown in the children (Table 2, Fig. 2). Third, the children showed activation in right precentral/postcentral gyri not seen in the adults. 


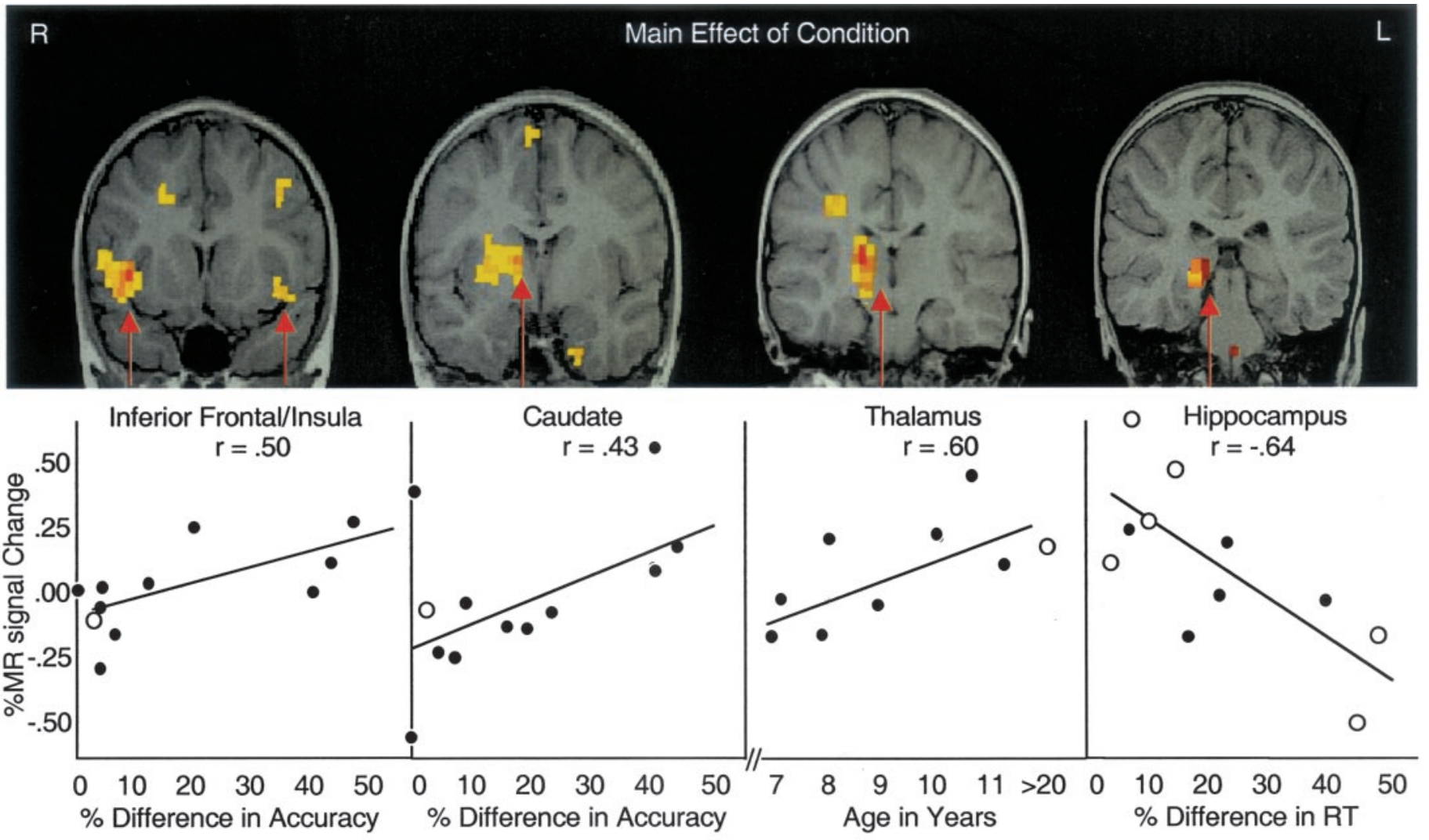

Figure 1. Loalization of regions of significant activity during the incompatible mapping condition relative to the compatible mapping condition across all subjects is presented in the top half. The graphs from left to right show (1) percent change in MR signal intensity in the inferior frontal cortex/insula cortex as a function of percent change in accuracy for incompatible relative to compatible trials, (2) percent change in MR signal intensity in the caudate nucleus as a function of accuracy, (3) percent change in MR signal intensity in the thalamus for incompatible trials as a function of the child's age, (4) percent change in MR signal intensity in the hippocampus as a function of percent change in reaction time for incompatible relative to compatible trials. Closed circles are data from children, and open circles are data from adults.

Table 2. Location, maximum $F$ ratios, and volume for regions showing a significant interaction of group (children and adults) $\times$ condition (incompatible and compatible) by magnitude in volume of activity

\begin{tabular}{|c|c|c|c|c|c|}
\hline \multirow[b]{2}{*}{ Regions of interest } & \multicolumn{3}{|c|}{ Talairach coordinates } & \multirow[b]{2}{*}{ Maximum $F$ ratio } & \multirow[b]{2}{*}{ Volume, $\mathrm{mm}^{3}$} \\
\hline & $X$ & $Y$ & $Z$ & & \\
\hline \multicolumn{6}{|l|}{ Children $>$ adults } \\
\hline Right parahippocampal gyrus (22/23) & 26 & -22 & -17 & 29.31 & 2831 \\
\hline Right basal ganglia & 10 & 5 & -2 & 20.92 & 1514 \\
\hline Right postcentral gyrus (1/2) & 33 & -23 & 42 & 45.39 & 1025 \\
\hline Left fusiform (37) & -28 & -45 & -19 & 21.26 & 537 \\
\hline Left cerebellum & -14 & -43 & -43 & 18.68 & 391 \\
\hline Right inferior parietal lobule (40) & 38 & -30 & 21 & 21.30 & 244 \\
\hline \multicolumn{6}{|l|}{ Adults $>$ children } \\
\hline Left middle frontal gyrus (6) & -37 & -5 & 32 & 22.30 & 683 \\
\hline Right middle frontal gyrus (6) & 40 & -4 & 44 & 27.08 & 488 \\
\hline
\end{tabular}

\section{Correlations with performance across ages}

Reaction times (RT) and accuracies were converted to percent difference scores to relate them to the MR signal [e.g., (RT for incompatible mapping - RT for compatible mapping)/RT for compatible mapping]. Two percent difference scores were calculated per subject for each incompatible mapping of 3-1-2 and 2-3-1 for both reaction time and accuracy. A correlational analysis was performed on these percent difference scores for accu- racy and reaction times with percent differences in MR signal for regions identified as significant for the main effect of condition (Table 1, Fig. 1). To minimize the number of correlations, only regions with the most robust signal change for the main effect (i.e., $F$ ratio $>25.00$ ) were included (Table 1 ).

Reaction time percent difference scores were positively correlated with percent difference in the MR signal in the hippocampus $(r=-0.57 ; p<0.003 ; n=22)$, with a greater signal change 


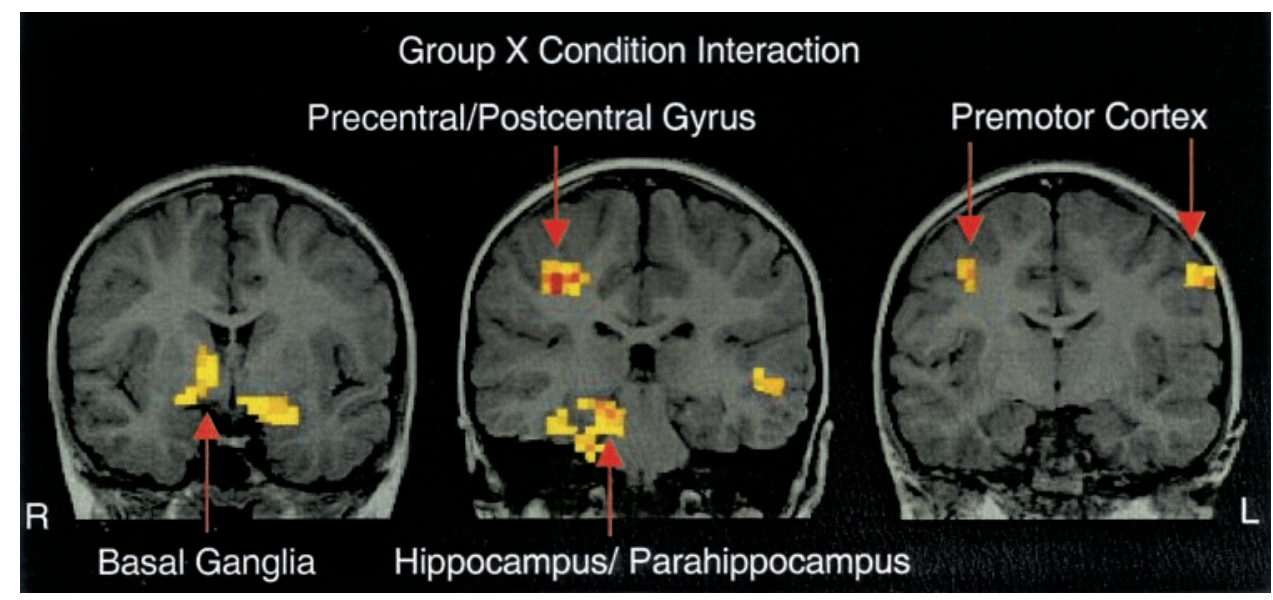

Figure 2. Localization of brain regions showing a robust MR signal change for the interaction of group (children, adults) $\times$ condition (incompatible, compatible) interaction. $R$, Right; $L$, left.

the right ventral prefrontal cortex, the ventral caudate nucleus,

in this region for individuals with the least increase in latency for the incompatible trials (Fig. 1). This correlation remained significant after excluding poor performers $(r=-0.62 ; p<0.004 ; n=$ 16) and children $(r=-0.77 ; p<0.0005 ; n=12)$, thus eliminating potential spurious correlations related to speed-accuracy tradeoffs and/or age-dependent change.

Although less compelling, percent differences in accuracy were correlated with MR signal changes in the striatum $(r=0.41 ; p<$ $0.04 ; n=22)$ and insula $(r=0.50 ; p<0.01 ; n=22)$. Given that accuracy was correlated with age $(r=0.50 ; p<0.02 ; n=18)$ and adults were near ceiling performance $(98.8 \%)$, correlations were performed separately for children. These correlations are plotted in Figure 1 for the striatum and ventral prefrontal cortex relative to the mean MR signal change for adults.

\section{Correlations specific to age}

Within children, there was a positive correlation between age and MR signal change in the thalamus $(r=0.60 ; p<0.03 ; n=8)$, but no other region correlated with age for either or both age groups. These data are plotted in Figure 1 relative to the mean MR signal change for adults, showing a change that mimics that of the adults with increasing age.

\section{DISCUSSION}

This study examined the neural circuitry involved in overriding a well learned stimulus-response mapping in favor of a new one. The largest volumes of activity were in the ventral prefrontal cortex, ventral caudate nucleus, thalamus, and hippocampus. There were specific developmental and performance effects shown in these common regions of activity for children and adults as well as disparate regions of activation between age groups.

\section{Developmental differences}

The ability to override a well learned response in favor of a new one is not fully developed in school-aged children. The evidence for continued development of this ability is indexed both behaviorally and physiologically in the current study. Behavioral performance in mean accuracy for adults was superior to that in children, and there was differential recruitment of brain regions between the age groups. However, there were also similarities. First, children and adults showed almost identical costs in reaction time for the incompatible relative to the compatible mapping condition, and children and adults activated similar brain regions.

\section{Common task-specific brain regions}

Common brain regions recruited by both children and adults when performing the stimulus-response compatibility task were and portions of the thalamus. These brain regions represent the projection zones within a previously described ventral prefrontal basal ganglia thalamocortical circuit that has been linked to flexibility in shifting a behavioral set (Alexander and Crutcher, 1990). That the activity in frontostriatal regions was lateralized to the right is consistent with both the imaging (Luna et al., 2001) and clinical literature (Castellanos et al., 1996; Casey et al., 1997a), implicating this circuitry in behavioral inhibition. Frontostriatal activity has also been shown in studies that compare novel actions relative to a repeated series of actions in serial reaction-time tasks (Grafton et al., 1995; Berns et al., 1997; Rauch et al., 1998). In the current study, activity in these regions correlated with behavioral performance with greater activity in individuals who had more difficulty in accurately overriding the well learned stimulus-response association. These findings may reflect stronger interference from the old stimulus-response mapping and are consistent with immature cognition being characterized by susceptibility to interference because these correlations were primarily driven by the children (adults were near ceiling in performance). The findings are also consistent with the clinical literature, which shows increased activity in this circuitry in OCD, in which the individual has difficulty shifting out of a specific behavioral or thought pattern (Baxter et al., 1988; Swedo et al., 1989).

Another common brain region recruited by both age groups was the hippocampus. Hippocampal activity correlated with the efficiency in making a novel mapping, as evidenced by shorter percent differences in reaction time for the incompatible relative to compatible mapping condition. There was no difference in this measure as a function of age, reflecting individual rather than developmental variability in this measure. The hippocampal activity during performance of this task is consistent with literature implicating hippocampus-related circuitry in the explicit learning of new associations (Squire, 1992; Gabrieli et al., 1994), particularly in the context of reversing an association between a stimulus and a spatial location (Murray et al., 1998). The right lateralization of hippocampal activity may be associated with spatial characteristics of the task, given that responses were remapped to new spatial locations. Such an interpretation would be consistent with the role of the right hippocampus in spatial memory and retrieval (Maguire et al., 1996; Tulving et al., 1996)

Taking these results together, one can dissociate the contributions of striatum- and hippocampus-related circuitry in the performance of a simple stimulus-response compatibility task. Accordingly, striatal circuitry appears to be involved in indexing the 
extent of interference from the habitual or well learned stimulusresponse association (Grafton et al., 1995; Berns et al., 1997; Rauch et al., 1998). Hippocampal circuitry, on the other hand, appears to be involved in the explicit learning and retrieval of associations between a stimulus and spatial response mapping.

\section{Developmental differences within common brain regions}

We observed varying degrees of activity in both magnitude and volume within both the ventral frontostriatal circuitry and the hippocampal region, depending on the age and performance of the subject. For instance, the magnitude of the MR signal change appeared to increase from 7 to 11 years in the thalamus, becoming more adultlike with age. This was similar for the ventral prefrontal cortex and striatum in that activity in these regions decreased, with increasing accuracy, as seen in adults.

For the basal ganglia and hippocampal regions we showed extensions in the volume of activity ventrally in children relative to adults. Thus, regional activity is larger and less focal in the immature brain relative to the adult brain. This pattern is consistent with previous studies, which reported more diff use regions of activity (Casey et al., 1997b; Hertz-Pannier et al., 1997) and greater subcortical activity in children (Luna et al., 2001), suggesting an immaturity in the refinement and organization of frontostriatal circuitry.

\section{Developmental differences within disparate brain regions}

When directly comparing children with adults, we showed that adults activated portions of the premotor cortex during new stimulus-response mappings not shown in the children. The adults may have activated the premotor cortex during the incompatible trials to help them maintain the representation of the new stimulus-response mapping. Thomas et al. (1999) and others (Braver et al., 1997) have shown activity in this region in working memory tasks that require the representation of similar task demands. Interestingly, similar regions have been reported by Petersen et al. (1998) to come on-line after extensive practice on tasks.

Children activated subcortical regions more than adults did, with the activity extending more ventrally in portions of the basal ganglia, thalamus, and parahippocampus. These results are similar to a previous developmental neuroimaging study by Luna et al. (2001). There are a number of possible interpretations for this finding. For example, it is well known that iron concentrations, which can affect MR signal intensity, increase with age and are most prominent in the basal ganglia (Schenker et al., 1993; Vymazal et al., 1995). Thus, greater iron deposition could result in less activity in this region for adults. However, there is less iron accumulation in portions of the hippocampus and thalamus; yet these regions show striking developmental differences as well. So this explanation would not be sufficient to account for all the observed developmental differences. Another possibility is that developmental differences in morphometry could explain the functional differences. Although MRI-based morphometry studies show no differences in overall cerebral cortex or total brain volume across the ages tested (7-30 years) (Jernigan and Tallal, 1990; Jernigan et al., 1991; Caviness et al., 1996; Giedd et al., 1996a,b; Reiss et al., 1996), there are regional differences in the basal ganglia (Jernigan et al., 1991; Giedd et al., 1996a; Thompson et al., 2000) and hippocampus (Giedd et al., 1996b; Pfluger et al., 1999; Szabo et al., 1999; Utsunomiya et al., 1999). These morphometric changes are not sufficient to account for the current findings of greater activity for children relative to adults because hippocampal volume increases over these age ranges rather than decreases. An interpretation perhaps more consistent with previous work is that the larger subcortical regions of activity reflect a delay in maturity of this circuitry, with less diff use and more focal patterns of activity in these regions in the mature system, similar to previous imaging studies of development $(\mathrm{Ca}-$ sey, 1997b; Hertz-Pannier et al., 1997; Luna et al., 2001) and learning (Karni et al., 1995).

Another example of disparate brain regions between children and adults was shown in portions of the right precentral and postcentral gyrus for children, but not adults. One interpretation for this activity is that the children activated the sensorimotor cortex bilaterally when learning the new stimulus-response mapping, whereas adults predominantly activated left sensorimotor regions that subtracted out when compared with the compatible mapping. Such bilateral activity is consistent with refined organization of right motor responses in right-handed adults to the contralateral sensorimotor cortex, but less discretely organized representations in the child. This interpretation is consistent with other reports of more bilateral activity in children than in adults in visuospatial tasks (Moses et al., 2002).

\section{Conclusions}

Our findings as a whole are consistent with much of the imaging literature on stimulus-response compatibility (Taylor et al., 1993; Iacoboni et al., 1996; Dassonville et al., 2001) and also the animal literature of neuronal recordings in the dorsal premotor cortex of nonhuman primates (Crammond and Kalaska, 1994; Riehle et al., 1994). We show evidence for the maturation and recruitment of common and disparate brain regions in children and adults during the suppression of overlearned stimulus-response mappings in favor of new ones. Furthermore, our findings are consistent with the involvement of ventral prefrontal basal ganglia thalamocortical circuitry in the maintenance of a behavioral set (Alexander et al., 1986; Casey et al., 2001, 2002). Finally, we provide an example of how developing systems can inform and help dissociate differential contributions of different learning systems. Using this approach we dissociated the contributions of striatal and hippocampal regions in the explicit learning of a new stimulus-response association.

\section{REFERENCES}

Alexander GE, Crutcher MD (1990) Functional architecture of basal ganglia circuits: neural substrates of parallel processing. Trends Neurosci 13:266-171.

Alexander GE, DeLong MR, Strick PL (1986) Parallel organization of functionally segregated circuits linking basal ganglia and cortex. Annu Rev Neurosci 9:357-381.

Baddeley AD (1986) Working memory. New York: Oxford UP.

Baxter Jr LR, Schwartz JM, Mazziotta JC, Phelps ME, Pahl JJ, Guze BH Fairbanks L (1988) Cerebral glucose metabolic rates in nondepressed patients with obsessive-compulsive disorder. Am J Psychiatry 145:1560-1563.

Berns GS, Cohen JC, Mintun MA (1997) Brain regions responsive to novelty in the absence of awareness. Science 276:1272-1275.

Brainerd CJ, Reyna VF (1993) Domains of fuzzy trace theory. In: Emerging themes in cognitive development, Vol 1 (Howe ML, Pasnak R, eds), pp. 50-93. New York: Springer.

Braver TS, Cohen JD, Nystrom LE, Jonides J, Smith EE, Noll DC (1997) A parametric study of prefrontal cortex involvement in human working memory. NeuroImage 5:49-62.

Casey BJ, Castellanos X, Giedd J, Marsh W, Hamburger S, Schubert A, Vauss Y, Vaituzis C, Dickstein D, Sarfatti S, Rapoport JL (1997a) Involvement of right frontostriatal circuitry in response inhibition deficits of attention deficit hyperactivity disorder. J Am Acad Child Adolesc Psychiatry 36:374-383.

Casey BJ, Trainor RJ, Orendi JL, Schubert AB, Nystrom LE, Giedd JN, 
Castellanos FX, Haxby JV, Noll DC, Cohen JD, Forman SD, Dahl RE, Rapoport JL (1997b) A developmental functional MRI study of prefrontal activation during performance of a go-no-go task. J Cogn Neurosci 9:835-847.

Casey BJ, Durston S, Fossella JA (2001) Evidence for a mechanistic model of cognitive control. Clin Neurosci Res 1:267-282.

Casey BJ, Tottenham N, Fossella J (2002) Clinical, imaging, lesion, and genetic approaches toward a model of cognitive control. Dev Psychobiol 40:237-254.

Castellanos FX, Giedd JN, Marsh WL, Hamburger SD, Vaituzis AC, Dickstein DP, Sarfatti SE, Vauss YC, Snell JW, Lange N, Kaysen D, Krain AL, Ritchie GF, Rajapakse JC, Rapoport JL (1996) Quantitative brain magnetic resonance imaging in attention-deficit hyperactivity disorder. Arch Gen Psychiatry 53:607-616.

Caviness Jr VS, Kennedy DN, Richelme C, Rademacher J, Filipek PA (1996) The human brain age 7-11 years: a volumetric analysis based on magnetic resonance images. Cereb Cortex 6:726-736.

Cohen JD, Servan-Schreiber D (1992) Context, cortex and dopamine: a Connectionist approach to behavior and biology in schizophrenia. Psychol Rev 99:47.

Crammond DJ, Kalaska JF (1994) Modulation of preparatory neuronal activity in dorsal premotor cortex due to stimulus-response compatibility. J Neurophysiol 71:1281-1284.

Dassonville P, Lewis SM, Zhu XH, Ugurbil K, Kim SG, Ashe J (2001) The effect of stimulus-response compatibility on cortical motor activation. NeuroImage 13:1-14.

Dempster FN (ed) (1993) Resistance to interference: developmental changes in a basic processing mechanism, Vol 1. New York: Springer.

Desimone R, Duncan J (1995) Neural mechanisms of selective visual attention. Annu Rev Neurosci 18:193-222.

Diamond A (1990) Rate of maturation of the hippocampus and the developmental progression of children's performance on the delayed non-matching to sample and visual paired comparison tasks. Annu Rev NY Acad Sci 608:394-426.

Gabrieli JD, Keane MM, Stanger BZ, Kjelgaard MM, Corkin S, Growdon JH (1994) Dissociations among structural-perceptual, lexical-semantic, and event-fact memory systems in Alzheimer, amnesic, and normal subjects. Cortex 30:75-103.

Giedd JN, Snell JW, Lange N, Rajapakse JC, Casey BJ, Kozuch PL, Vaituzis AC, Vauss YC, Hamburger SD, Kaysen D, Rapoport JL (1996a) Quantitative magnetic resonance imaging of human brain development: ages 4-18. Cereb Cortex 6:551-560.

Giedd JN, Vaituzis AC, Hamburger SD, Lange N, Rajapakse JC, Kaysen D, Vauss YC, Rapoport JL (1996b) Quantitative MRI of the temporal lobe, amygdala, and hippocampus in normal human development: ages 4-18 years. J Comp Neurol 366:223-230.

Grafton ST, Waters C, Sutton J, Lew MF, Couldwell W (1995) Pallidotomy increases activity of motor association cortex in Parkinson's disease: a positron emission tomographic study. Ann Neurol 37:776-783.

Harnishfeger KK, Bjorkland F (1993) The ontogeny of inhibition mechanisms: a renewed approach to cognitive development. In: Emerging themes in cognitive development, Vol 1 (Howe ML, Pasnak R, eds), pp 28-49. New York: Springer.

Hertz-Pannier L, Gaillard WD, Mott SH, Cuenod CA, Bookheimer SY, Weinstein S, Conry J, Papero PH, Schiff SJ, Le Bihan D, Theodore WH (1997) Noninvasive assessment of language dominance in children and adolescents with functional MRI: a preliminary study. Neurology 48:1003-1012.

Iacoboni M, Woods RP, Mazziotta JC (1996) Brain-behavior relationships: evidence from practice effects in spatial stimulus-response compatibility. J Neurophysiol 76:321-331.

Iversen SD, Mishkin M (1970) Perseverative interference in monkeys following selective lesions of the inferior prefrontal convexity. Exp Brain Res 11:376-386.

Jernigan TL, Tallal P (1990) Late childhood changes in brain morphology observable with MRI. Dev Med Child Neurol 32:379-385.

Jernigan TL, Trauner DA, Hesselink JR, Tallal PA (1991) Maturation of human cerebrum observed in vivo during adolescence. Brain 114:2037-2049.

Kahneman D, Treisman A, Burkell J (1983) The cost of visual filtering. J Exp Psychol Hum Percept Perform 9:510-522.

Karni A, Meyer G, Jezzard P, Adams MM, Turner R, Ungerleider LG (1995) Functional MRI evidence for adult motor cortex plasticity during motor skill learning. Nature 377: 155-158.

Luna B, Garver KE, Merriam EP, Minshew NJ, Keshavean MS, Thulborn KR, Weeney JA (2001) Develpmental fMRI studies of spatial working memory form late childhood. NeuroImage 13:786-793.
Luria DM (1961) The role of speech in the regulation of normal and abnormal behavior. New York: Basic Books.

Maguire EA, Frackowiak RS, Frith CD (1996) Learning to find your way: a role for the human hippocampal formation. Proc R Soc Lond B Biol Sci 263:1745-1750.

Moses P, Roe K, Buxton R, Wong EC, Frank LR, Stiles J (2002) Functional MRI of global and local processing in children. NeuroImage $16: 415-424$

Munakata Y, Yerys BE (2001) All together now: when dissociations between knowledge and action disappear. Psychol Sci 12:335-337.

Murray EA, Baxter MG, Gaffan D (1998) Monkeys with rhinal cortex damage or neurotoxic hippocampal lesions are impaired on spatial scene learning and object reversals. Behav Neurosci 112:1291-1303.

Petersen SE, van Mier H, Fiez J, Rachle ME (1998) The effects of practice on the functional anatomy of task performance. Proc Natl Acad Sci USA 95:853-860.

Pfluger T, Weil S, Weis S, Vollmar C, Heiss D, Egger J, Scheck R, Hahn K (1999) Normative volumetric data of the developing hippocampus in children based on magnetic resonance imaging. Epilepsia 40:414423.

Rauch SL, Whalen PJ, Curran T, McInerney S, Heckers S, Savage CR (1998) Thalamic deactivation during early implicit sequence learning: a functional MRI study. NeuroReport 9:865-870.

Rauch SL, Whalen PJ, Curran T, Shin LM, Coffey BI, Savage CR, McInerney SC, Baer L, Jenike MA (2001) Probing striato-thalamic function in obsessive-compulsive disorder and Tourette syndrome using neuroimaging methods. Adv Neurol 85:207-224.

Reiss AL, Abrams MT, Singer HS, Ross JL, Denckla MB (1996) Brain development, gender and IQ in children: a volumetric imaging study. Brain 119:1763-1774.

Riehle A, Kornblum S, Requin J (1994) Neuronal coding of stimulusresponse association rules in the motor cortex. NeuroReport 5:2462-2464.

Schenker C, Meier D, Wichmann W, Boesiger P, Valavanis A (1993) Age distribution and iron dependency of the $\mathrm{T} 2$ relaxation time in the globus pallidus and putamen. Neuroradiology 35:119-124.

Shallice T (1988) From neuropsychology to mental structure. New York: Cambridge UP.

Squire LR (1992) Memory and the hippocampus: a synthesis from findings with rats, monkeys, and humans. Psychol Rev 99:195-231.

Swedo SE, Pietrini P, Leonard HL, Schapiro MB, Rettew DC, Goldberger EL, Rapoport SI, Rapoport JL, Grady CL (1989) Cerebral glucose metabolism in childhood-onset obsessive-compulsive disorder. Arch Gen Psychiatry 49:690-694.

Szabo CA, Wyllie E, Siavalas EL, Najm I, Ruggieri P, Kotagal P, Luders H (1999) Hippocampal volumetry in children 6 years or younger: assessment of children with and without complex febrile seizures. Epilepsy Res 33:1-9.

Taylor SF, Kornblum S, Minoshima S, Oliver LM, Koeppe RA (1993) Changes in medial cortical blood flow with a stimulus-response compatibility task. Neuropsychologia 32:249-255.

Thomas KM, King SW, Franzen PL, Welsh TF, Berkowitz AL, Noll DC Birmaher V, Casey BJ (1999) A developmental functional MRI study of spatial working memory. NeuroImage 10:327-338.

Thompson PM, Giedd JN, Woods RP, MacDonald D, Evans AC, Toga AW (2000) Growth patterns in the developing brain detected by using continuum mechanical tensor maps. Nature 404:190-193.

Tipper SP, Bourque TA, Anderson SH, Brehaut JC (1989) Mechanisms of attention: a developmental study. J Exp Child Psychol 48:353-378.

Tulving E, Markowitsch HJ, Craik FE, Habib R, Houle S (1996) Novelty and familiarity activations in PET studies of memory encoding and retrieval. Cereb Cortex 6:71-79.

Utsunomiya H, Takano K, Okazaki M, Mitsudome A (1999) Development of the temporal lobe in infants and children: analysis by MRbased volumetry. Am J Neuroradiol 20:717-723.

Vaidya CJ, Austin G, Kirkorian G, Ridlehuber HWQ, Desmond JE, Glover GH, Gabrieli DE (1998) Selective effects of methylphenidate in attention deficit hyperactivity disorder: a functional magnetic resonance study. Proc Natl Acad Sci USA 95:14494-14499.

Vymazal J, Hajek M, Patronas N, Giedd J-N, Bulte J-W, Baumgarner C, Tran V, Brooks R-A (1995) The quantitative relation between T1weighted and T2-weighted MRI of normal gray matter and iron concentration. J Magn Reson Imaging 5: 554-560.

Woods RP, Cherry SR, Mazziotta JC (1992) Rapid automated algorithm for aligning and reslicing PET images. J Comput Assist Tomogr 16:620-633.

Zelazo PD, Burack JA, Benedetto E, Frye D (1996) Theory of mind and rule use in individuals with Down's syndrome: a test of the uniqueness and specificity claims. J Child Psychol Psychiatry 37:479-484. 